\title{
Estudos sobre a vegetação das Campinas Amazonicas IV \\ Estudos ecológicos na Campina da Reserva Biológica INPA - SUFRAMA (Manaus-Caracaraí, km 62)
}

\author{
Marilene Marinho Nogueira Braga (") \\ Pedro Ivo Soares Braga (")
}

\section{Resumo}

Para complementar o trabalho de Anderson et al. (trabalho anterior) sobre a vegetação da campina, foram investigados três aspectos ecológi$\cos$ adicionais, os quais não constavam na progra mação dos trabalhos de tese dos alunos do mestrado do INPA. No primeiro estudo, analisadas 50 ilhas pequenas que ocorrem na campina aberta (1). com um total de 25 espécies de plantas lenhosas e algumas plantas herbáceas, relacionando-se o ta manho das ilhas, a ocorrência das espécies e as associações entre as mesmas. No segundo, verificada a ocorrência de duas espécies de Loranthaceae, hemiparasitas, que ocorrem na campina aberta e sombreada (1), com tendência a terem hospedeiros especificos. Phthirusa rufa (Mart.) Eichl. (Loranthaceae) tem como hospedeiro Ouratea spruceana Engl. (Ochnaceae) e Phthirusa micrantha Eichl. (Loranthaceae) tende, entre outras espécies, a parasitar Hirtella racemosa Lam. var. racemosa (Chrysobalanaceae). Aspectos anatômicos e ecofisiológicos foram relacionados. No último trabalho ecológico foi analisada a ocorrência de algumas epífitas em cinco espécies de árvores na campina (aberta e sombreada) e na campinarana.

\section{1 - ESTUDO DE ASSOCIAÇÕES DE PLANTAS EM PEQUENAS ILHAS DE UMA CAMPINA DA AMAZONNIA CENTRAL}

\section{INTRODUÇĀO}

O presente trabalho resulta da necessidade de responder a uma parte das questões que são feitas sobre a campina; trata-se de um levantamento botânico das espécies que ocorrem nas pequenas ilhas situadas nas áreas mais abertas, tendo em vista verificar a ocorrência de associação entre as espécies de cada ilha e a ocorrência das espécies em relação à área das ilhas.

É conveniente ressaltar, o importante papel que estas pequenas comunidades vegeta- cionais representam, sob o aspecto de colonização numa região de solo arenoso, com temperatura do ar elevada e intensa luminosidade.

\section{MATERIAL E MÉTODO}

O estudo foi realizado na Reserva Biológica de Campina do INPA, localizada no $\mathrm{km} 62$ da estrada Manaus-Caracaraí .

Foram escolhidas duas regiões com predominância de pequenas ilhas de vegetação subarbustiva (campina aberta) e, de cada iha coletamos material para identificação e foram anotadas :

- espécies que ocorrem;

- duas medidas de diâmetro perpendiculares entre si (as ilhas têm de um modo geral a forma de uma elipse), com as quais foram calculadas as áreas das ilhas.

O material coletado toi identificado por comparação com as plantas do Herbário do INPA. As amostras testemunhas são as mesmas citadas no traba!ho de Anderson et alii (1975). com algumas exceções, as quais indicamos na lista das espécies encontradas nas ilhas (campina aberta).

\section{REsultados}

As espécies encontradas nas ilhas são as seguintes :

\section{Plantas lenhosas}

$\begin{array}{cc}\text { - Apocynaceae - } & \text { Mandevilla ulei K. } \\ & \text { Schum. } \\ & \text { Tabernaemontana rupico- } \\ & \text { la Benth. } \\ \text { - Burseraceae -- Protium heptaphyllum } \\ \text { (Aubl.) March. }\end{array}$

(") - Instituto Nacional de Pesquisas da Amazônia, Manaus

(1) - A terminologia empregada foi a utilizada por Lisbôa, Anderson et al. nos trabalhos anteriores. 
- Chrysobala-

naceae - Hirtella racemosa Lam. var. racemosa

- Compositae - Vernonia grisea Baker

- Euphorbiaceac- Mlabea occidenta. lis Benth.

- Gesneriaceae -- Codonanthe aff. crassifolia (Focke) Morton

- Guttiferae - Clusia cf. nemorosa G. F. W. Meyer.

- Leguminosae - Ormosia costulata (Miq.) Kleinh.

Swartzia dolicopoda Cowan.

- Loranthaceae - Phthirusa micrantha Eichl.

Phthirusa rufa (Mart.)

Eichl.

- Melastomaceae

-.- Sandemania hoehnei (Cogn.) Wurdack. Miconia lepidota DC.

- Myrsinaceae - Conomorpha cf. grandiflora Mez.

- Myrtaceae - Eugenia sp.

- Ochnaceae - Ouratea spruceana Eng!.

- Passifloraceae-- Passiflora faroana Harms

- Rubiaceae - Pagamea duckei Standl. Palicourea nitidella (M. Arg.) Standl.

Palicourea cf. Iupulina Benth. Psychotria barbiflora DC.

- Sapindaceae - Matayba opaca Radlk. Talisia cesarina (Benth.) Radlk.

- Sapotaceae - Glycoxylon inophyllum (Mart. ex Miq.) Ducke

\footnotetext{
- Asclepiadaceae $\rightarrow$ não identificada P.I.S. Braga 2937 et M.M.N. Braga, INPA 50142.

- Bromeliaceae - Aechmea mertensis (Meyer) Schult. f. - B. de Albuquerque 1075 , INPA 48626.
}

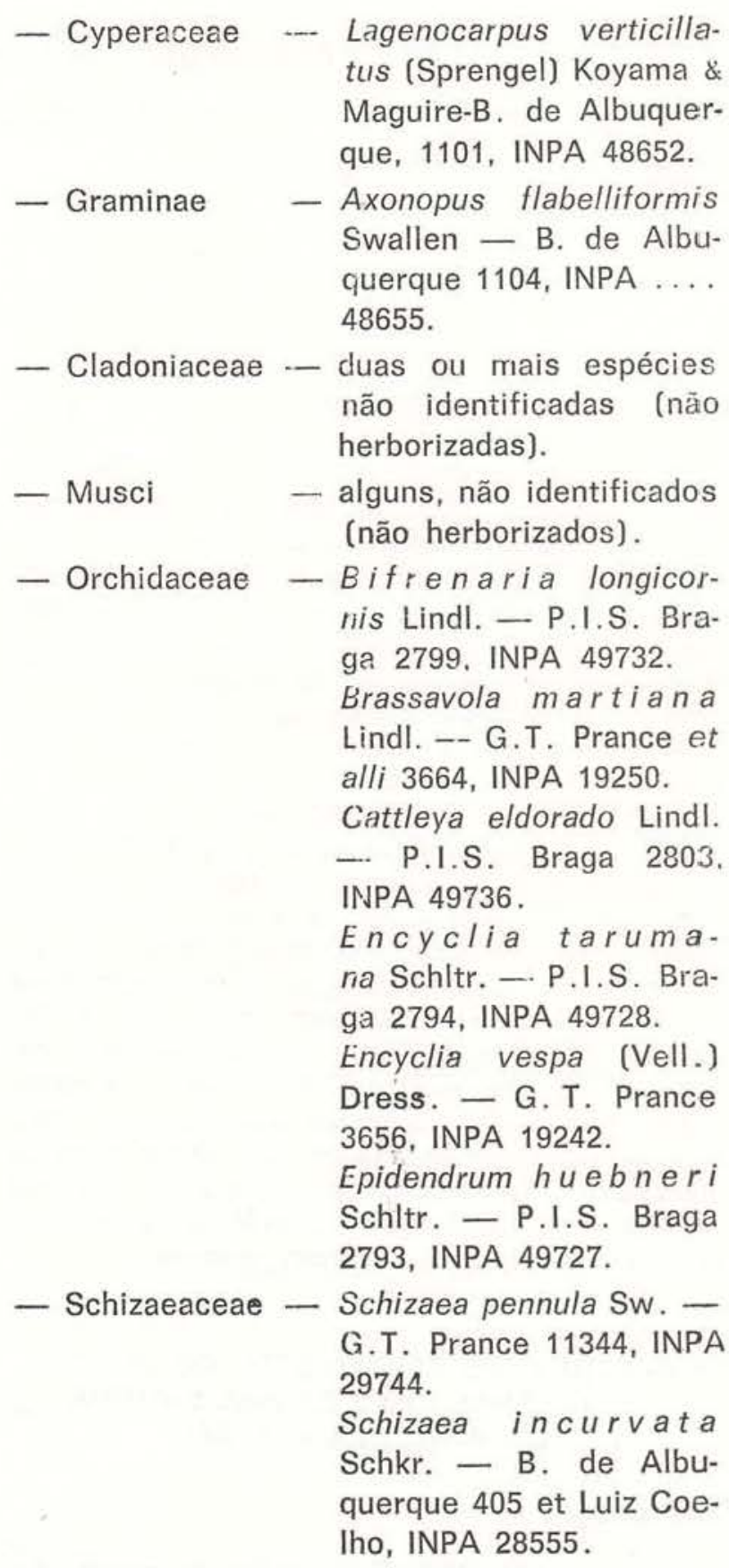

Os resultados básicos e derivações dos mesmos foram agrupados nas tabelas 1,2 e 3 .

Pela tabela $\{$, verifica-se que a diversidade especifica está intimamente relacionada com o tamanho da ilha. Nela apresentamos a percentagem de freqửência de todas as espécies.

$\mathrm{Na}$ tabela 2 estão relacionadas as espécies lenhosas que ocorrem com mais freqüência com uma percentagem acima de $20 \%$ ), e uma representação esquemática destas espécies nas ilhas. 


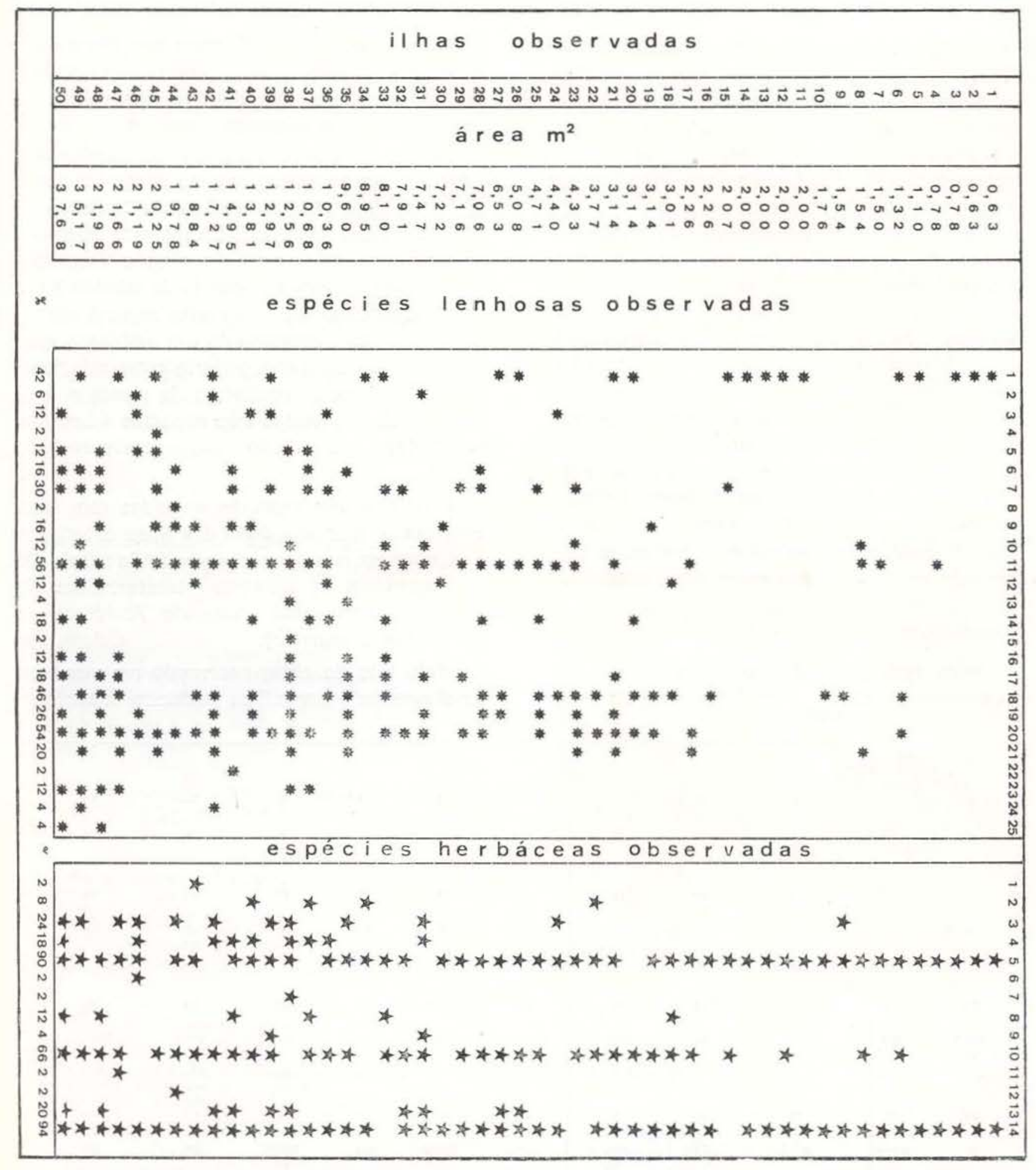

TABELA 1 - Distribuição de plantas lenhosas e herbáceas na Campina aberta. Espécies lenhosas observadas: 1 - Sandemania hoehnei, 2 - Miconia lepidota, 3 - Mabea occidentalis, 4 - Passiflora faroana, 5 Glycoxylon inophyllum, 6 - Hirtella racemosa var. racemosa, 7 - Eugenia sp., 8 - Ormosia costulata, 9 Swartzia dolicopoda, 10 - Talisia cesarina, 11 - Matayba opaca, 12 - Vernonia grisea, 13 - Clusia aff. nemorosa, 14 - Tabernaemontana rupicola 15 - Palicourea nitidella, 16 - Psychotria barbiflora, 17 - Pa. licourea lupulina Benth., 18 - Conomorpha ef. grandiflora, 19 - Protium heptaphyllum, 20 - Ouratea spru. ceana, 21 - Pagamea duckei, 22 - Mandevilla ulei, 23 - Codonanthopsis agreyata, 24 - Phthirusa rufa $25 \rightarrow$ Phthirusa micrantha.

Espécies herbáceas observadas: 1 - Asclepiadaceae, 2 - Schizaea incurvata, 3 - Schizaea pennula, 4 - Mus. ci, 5 - Cladoniaceae, 6 - Bifrenaria longicornis, 7 - Epidendrum huebneri, 8 - Cattleya eldorado, 9 Brassavola martiana, 10 - Encyclia tarumana, 11 - Encyclia vespa, 12 - Aechmea mertensis, 13 - Axonopus flabelliformis Swallen, 14 - Lagenocarpus verticillatus. 
Nas tabelas 3.1 e 3.2 representamos, em or dem decrescente de freqüência, o número de vezes que as espécies aparecem agrupadas dois a dois, três a três, quatro a quatro e cinco a cinco. Neste caso o número de vezes que cada associação ocorre deveria diminuir de cima para baixo e da esquerda para a direita (devido à freqüência de ocorrência das espécies) no entanto, verificamos que nos agrupamentos em que ocorre Sandemania hoehnei (Cogn.) Wurdack, o número de associações decresce bastante. Da mesma forma certas associações como: Matayba opaca + Eugenia sp.; Matayba opaca + Protium heptaphyllum; Ouratea spruceana + Eugenia sp.; Ouratea spruceana + Protium heptaphyllum; Conomorpha ct. grandiflora + Protium heptaphyllum; Matayba opaca + Ouratea spruceana + Protium heptaphyllum; Ouratea spruceana + Conomorpha cf. grandi. flora + Protium heptaphyllum e outras, aparecem com uma freqüência maior que a esperada.

\section{CONCLUSÕES}

Pelos resultados obtidos acreditamos ser Sandemania hoehnei (Cogn.) Wurdack uma es- pécie pioneira, mas com pouca tendência a associação; apesar de ocorrer numa percentagem de $42 \%$ das ithas observadas, poucas vezes desenvolve-se com outras plantas.

Outras espécies têm um comportamento difierente como por exemplo: Matayba opaca Radlk., Ouratea spruceana Engl. e Conomorpha cf. grandiflora Mez, que começam a aparecer em pequenas ilhas como pioneiras e desenvolvem-se bem em associações (vide tabelas $3.1 \mathrm{e}$ 3.2). Provavelmente, têm muita importância ao formarem ilhas, preparando um ambiente para outras espécies, o que poderia estar relacionado com a própria arquitetura da planta e área foliar total, que nestas três espécies é bem desenvolvida, permitindo um sombreamento maior.

A maioria das espécies anotadas tem uma ocorrência inferior a $20 \%$ das ilhas estudadas e só ocorrem nas ilhas maiores (vide tabela 1); correspondem às espécies características da "campina sombreada" segundo Anderson et aili (trabalho anterior).

Pelo fato de estar ocorrendo um aumento de diversidade específica podemos supor que,

\begin{tabular}{|c|c|c|c|c|c|c|c|c|c|c|}
\hline 1 & 2 & 3 & 4 & 5 & 6 & 7 & 8 & 9 & 10 & 11 \\
\hline M & $M$ & M & 0 & $M$ & RMS & 0 & ко & R & R & $m$ \\
\hline 12 & 13 & 14 & 15 & 16 & 17 & 18 & 19 & 20 & 21 & 22 \\
\hline $\mathrm{M}$ & $M$ & $M$ & $8 \mathrm{M}$ & $R$ & sok & R & RS & RM & $\begin{array}{c}\text { VMO } \\
\text { KS }\end{array}$ & RS \\
\hline 23 & 24 & 25 & 26 & 27 & 28 & 29 & 30 & 31 & 32 & 33 \\
\hline $\begin{array}{c}\text { RSOB } \\
\text { VK }\end{array}$ & RO & $\begin{array}{l}\text { RSO } \\
\text { BV }\end{array}$ & мо & $\underset{v}{\text { RMO }}$ & $\begin{array}{l}\text { SOR } \\
\text { BV }\end{array}$ & ose & & vso & osB & RSMOB \\
\hline 34 & 35 & 36 & 37 & 38 & 39 & 40 & 41 & 42 & 43 & 44 \\
\hline$M$ & SVRK & ROB & OSB & $\begin{array}{l}\text { SRO } \\
\text { VK }\end{array}$ & Sмо B & SRVO & Bo & $\underset{\text { VK }}{\text { SMOR }}$ & SR & so \\
\hline 45 & & 46 & & 47 & & 48 & & 49 & & 50 \\
\hline SMOB & & sov & & $S K R$ & & SORV & & MORK & & vso \\
\hline$k$ & & & & $M$ & & B & & SB & & E \\
\hline
\end{tabular}

TABELA 2 - Representação esquemática das espécies lenhosas que ocorrem nas ilhas da Campina aberta com percentagem acima de $20 \%$. O - Matayba opaca, M - Sandemania hoehnei, S - Ouratea spruceana. $\mathrm{R}$ - Conomorpha cf. grandiflora, B - Eugenia sp., V - Protium heptaphyllum, K - Pagamea duckei. 
atualmente, as ilhas da campina se encontrem num estágio inicial de sucessão (Odum, 1969).

Os dados de espécies não lenhosas são muito significativos em termos de sucessão. Os líquens (Cladoniaceae) aparecem mesmo isolados sobre a areia, comprovando que, realmente, são capazes de sobreviverem nos piores ambientes físicos (Odum, 1969). A ocorrência destes em $90 \%$ das ilhas nos sugare uma larga faixa de distribuição.

Uma espécie de Cyperaceae - Lagenocarpus verticillatus (Sprengel) Koyama \& Maguire, tem uma situação semelhante, aparece em 94\% das ilhas e mesmo isoladamente; já Encyclia tarumana Schltr. (Orchidaceae), encontra-se com uma freqüência elevada (vide tabela 1).

decresce o número de assoclaçōes

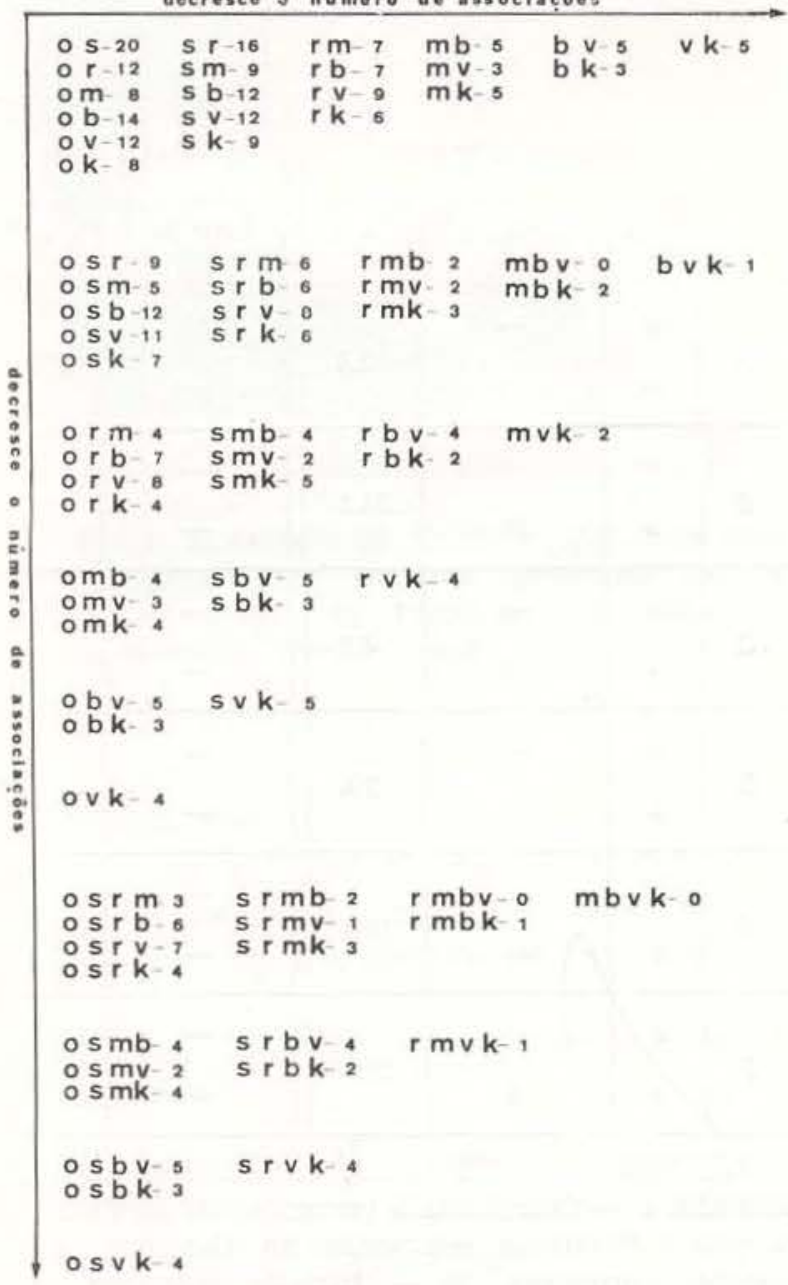

mas depende que líquens e outras plantas pro. piciem um microclima próprio para que se desenvolva, pois não ocorre isoladamente. As demais orquídeas ocorrem com uma freqüência muito baixa se comparada com a freqüência das mesmas na campinarana (Braga, inédito).

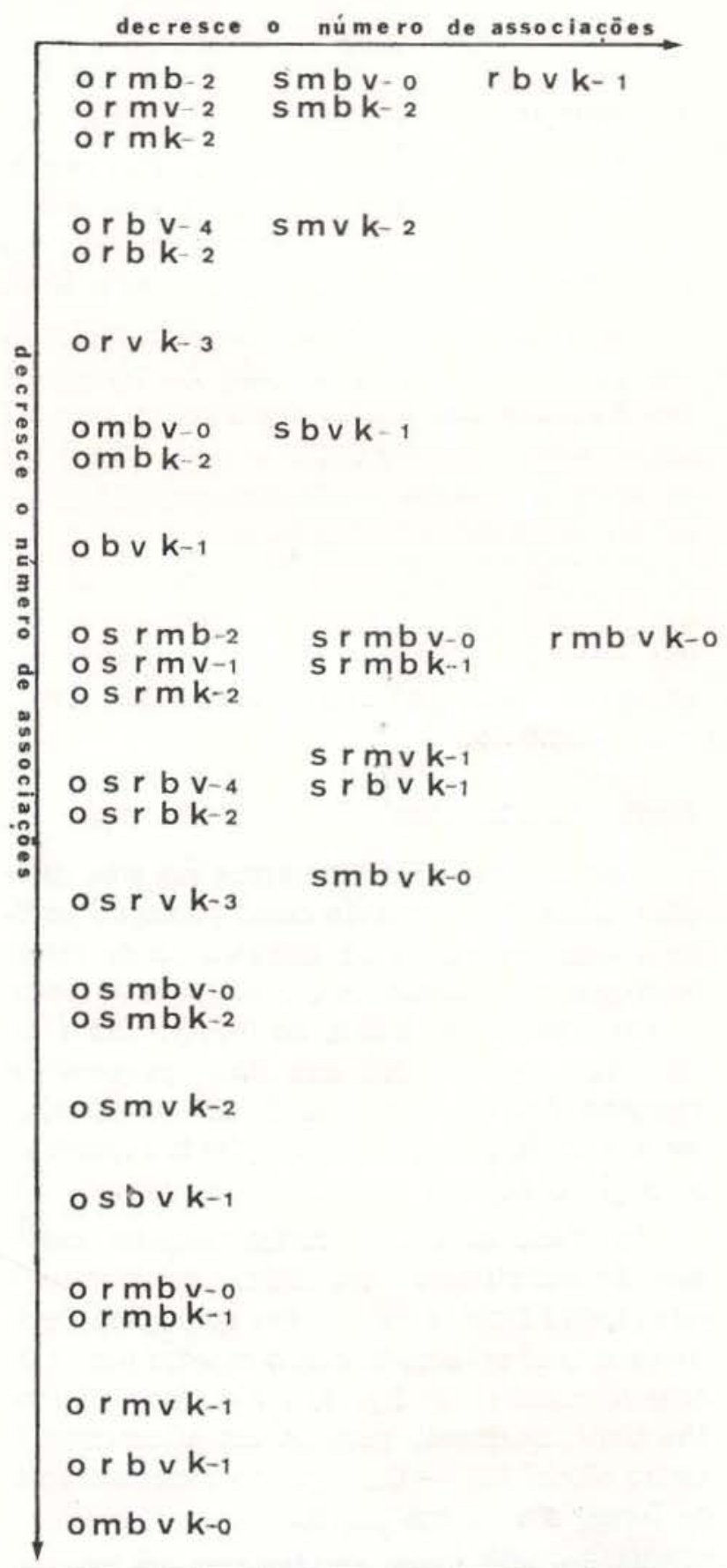

TABELAS $3.1-3.2$ - Representação em ordem decrescente de frequência do número de vezes que as espe cies aparecem agrupadas $2+2,3+3,4+4,5+5$. O - Matayba opaca, M - Sandemania hoehnei, S - Ouratea spruceana, R - Conomorpha ef. grandiflora, B - Eugenia sp., V - Protium heptaphyllum, K - Pagamea duckei. 
Resultados que confirmem nossos dados derivados da tabela 1 ou que sugiram novos aspectos de associação e sucessão para as plantas das pequenas ilhas da campina (campina aberta) estão sendo aguardados, pois, foram entregues para análise em computador, e seräo posteriormente divulgados.

\section{2 - ESTUdO SOBRE A OCORRENCIA DE LORANTHACEAE NA CAMPINA}

\section{INTRODUÇÃo}

Nas ilhas localizades na região da campina aberta e sombreada foi verificada a presença de duas espécies de Loranthaceae: Phthirusa rufa (Mart.) Eichl. e Phthirusa micrantha Eichl.

Em estudos anatômicos anteriores (Braga, inédito) de Phthirusa micraníha foi observado que a mesma não possui mecanismos que impeçam uma freqüente perda de água, o que era de se esperar numa planta que cresce em pleno sol sobre um solo arenoso.

Baseado neste aspecto, foi feito um estudo cuja finalidade era verificar quais as plantas que serviam como hospedeiros para as hemiparasitas e quais os efeitos resultantes deste relacionamento.

\section{MATERIAL E MÉTODO}

Foram feitos três transectos em três direções diferentes, tomando como ponto de partida a área mais seca da campina (onde estão localizados os postos de climatologia do Setor de Ciências do Ambiente do INPA). Todos os indivíduos encontrados nas ilhas pequenas $\mathrm{e}$ margens das ilhas grandes foram anotados, o mesmo foi feito em relação à planta suporte e, se o galho suporte estava vivo ou não.

Em trabalho à parte foram tomadas medidas de resistência estomática de Phthirusa rufa (Mart.) Eichl. e de Ouratea spruceana Engl. sobre a qual se encontrava, o mesmo para Hir. tella racemosa (ver fig. 1) e Phthirusa micrantha Eichl., utilizando para tal um Microamperimetro Model 220 - G., segundo a metodologia de Turner \& Parlange (1970).

As medidas foram obtidas com um intervalo de cerca de duas horas no período de 12:00 às $22: 00$ horas $(22.05 .75)$ e de $7: 30$ às $10: 30$ horas $(23.05 .75)$.

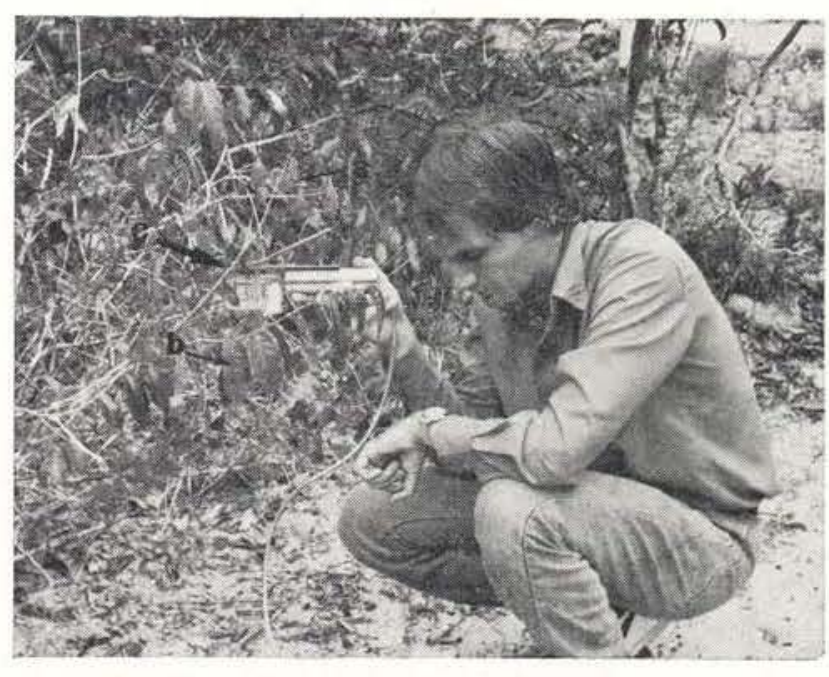

FIG. 1 - Foto da medição de resistência estomática na Campina aberta. a - Phthirusa micrantha, b - Hirtella racemosa var. racemosa, c - sensor do aparelho de medição de resistência estomática.

\begin{tabular}{|c|c|c|c|c|c|}
\hline & \multicolumn{3}{|c|}{ Phthirusa micrantha } & \multicolumn{2}{|c|}{ Phthirusa rufa } \\
\hline & & lividuos & $\%$ & $\begin{array}{c}\text { N.o de } \\
\text { individuos }\end{array}$ & $\%$ \\
\hline A & $\begin{array}{l}\mathrm{v} \\
\mathrm{s}\end{array}$ & - & 2,4 & $\begin{array}{l}10 \\
-\end{array}$ & 100 \\
\hline B & $\begin{array}{l}\mathrm{v} \\
\mathrm{s}\end{array}$ & $\begin{array}{r}1 \\
20\end{array}$ & 51,1 & - & \\
\hline C & $\begin{array}{l}\text { v } \\
\text { s }\end{array}$ & - & 4,8 & - & \\
\hline D & $\begin{array}{l}\mathrm{v} \\
\mathrm{s}\end{array}$ & $\begin{array}{c}- \\
1\end{array}$ & 2,4 & - & \\
\hline$E$ & $\begin{array}{l}\mathrm{v} \\
\mathrm{s}\end{array}$ & $\begin{array}{r}8 \\
-\end{array}$ & 19,5 & - & \\
\hline $\mathrm{F}$ & $\begin{array}{l}\mathrm{v} \\
\mathrm{s}\end{array}$ & $\frac{-}{8}$ & 19,5 & - & \\
\hline
\end{tabular}

TABELA 4 - Ocorrência e percentagem de Phthirusa rufa e Phthirusa micrantha na Campina. A Ouratea spruceana, B - Hirtella racemosa var racemosa, C - Eugenia sp., D - Glycoxylon inophyllum, E - Protium heptaphyllum; s - seca, v - verde; o - Phthirusa rufa, " Phthirusa micrantha. 

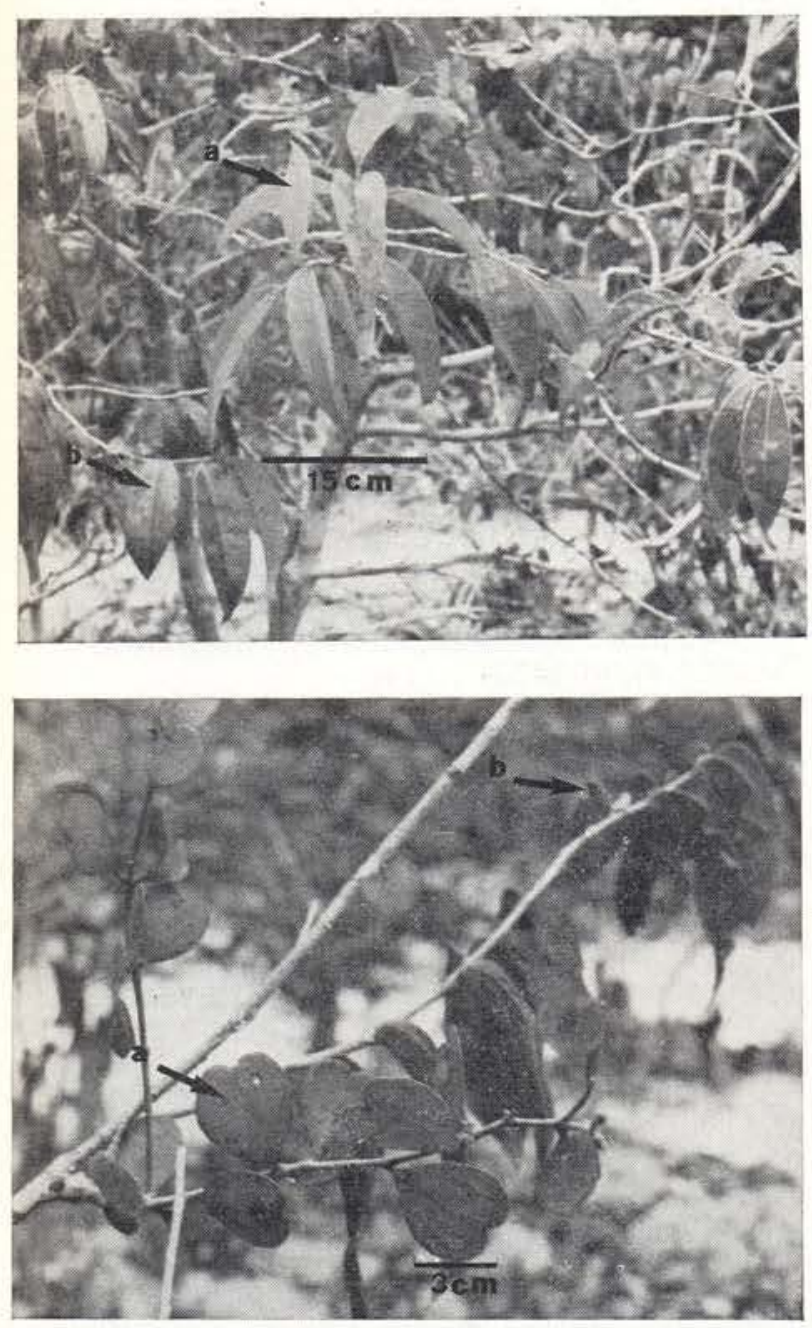

FIG. 2 e 3: 2, Aspecto da planta de Phthirusa rufa (a), hemiparasitando Ouratea spruceana (b). 3, Aspecto da planta de Phthirusa micrantha (a), hemiparasitando Hirtella racemosa var. racemos2 (b).

O material coletado foi identificado por comparação com as plantas do Herbário do INPA. As amostras testemunhas são as mesmas citadas no trabalho de Anderson et alii (1975).

\section{RESUITADOS}

$\mathrm{Na}$ tabela 4 temos os dados de ocorrência de Phthirusa rufa e Phthirusa micrantha em seus respectivos hospedeiros.

Observa-se que no caso de Phthirusa rufa todas as plantas encontradas ocorrem em Ouratea spruceana, não tendo sido observada em outras espécies de plantas. Quanto à
Phthirusa micrantha, esta tem ocorrência maior $(51,21 \%)$ em Hirtella racemosa. Alguns indivíduos ocorrem em Protium heptaphyllum (Aubl.) March. (Burseraceae) e Glycoxylon inophyllum (Mart. ex Miq.) Ducke (Sapotaceae) numa percentagem relativamente baixa $(19 \%)$; é muito rara a ocorrência em Eugenia sp. (Myrtaceae) $(4,87 \%)$, Ouratea spruceana e Pagamea duckei Standl. (Rubiaceae) $(2,43 \%)$.

Quanto ao aspecto dos galhos parasitados (ver tabela 4) observou-se que apenas em Glycoxylon inophyllum (Mart. ex Miq.) Ducke os galhos não estavam secos. Num indivíduo de Ouratea spruceana toda a planta estava seca. Em certos casos tornava-se difícil até mesmo a identificação do hospedeiro.

Nos gráficos 1 e 2 temos os resultados da resistência estomática de Phthirusa rufa e Ouratea spruceana, Phthirusa micrantha e Hirtella racemosa no intervalo e períodos citados anteriormente. Verificou-se (Gráfico 1), que nas horas mais quentes do dia e de maior intensidade

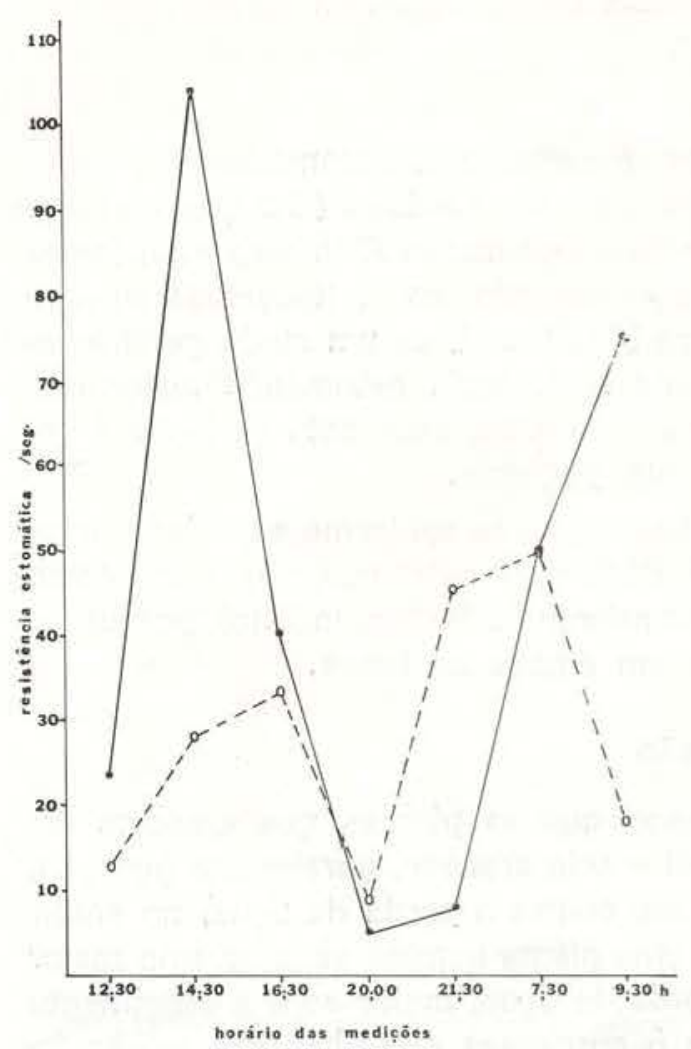

Q -0 Phthirusa rutal Mart. Elch C O Ouratea spruecana Engl.

GRAFICO 1 - Medição de resistência estomática em Phthirusa rufa e Ouratea spruceana. 


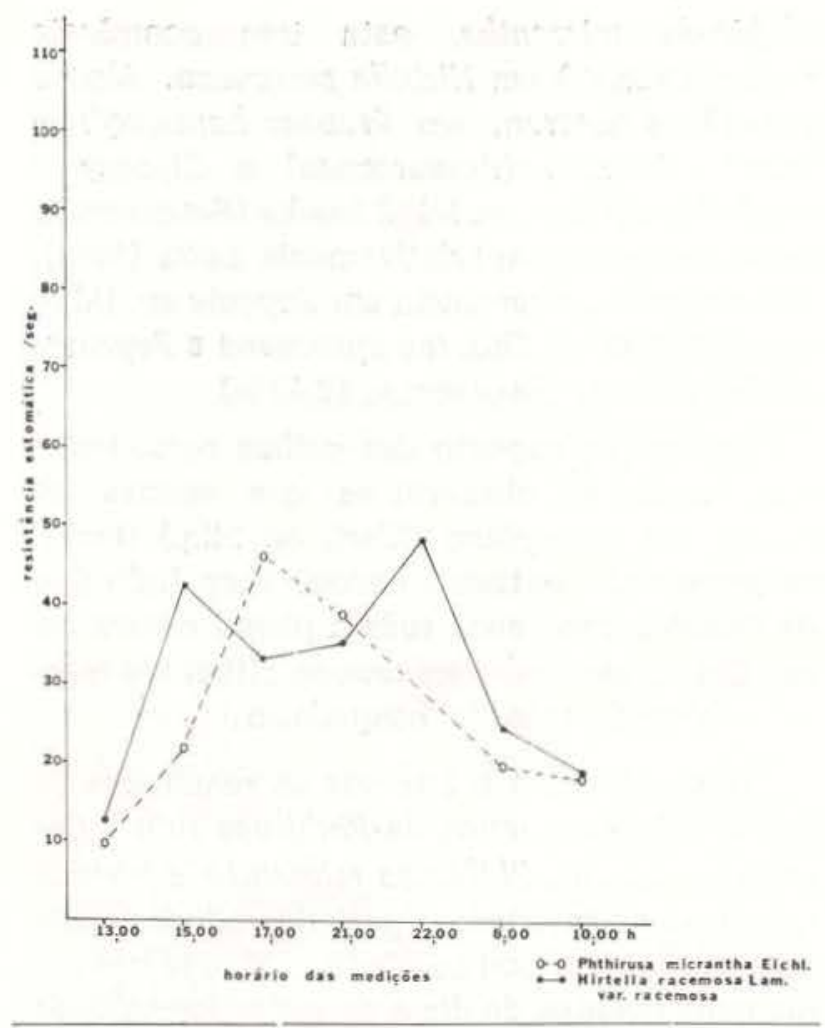

GRAFICO 2 - Medição de resistência estomática em Phthirusa micrantha e Hirtella racemosa var racemosa.

luminosa, a resistência estomática era muito maior na planta hospedeira (Ouratea spruceana) que na heraiparasita Phthirusa rufa, invertendo esta relação ac noitecer. Já Hirtella racemosa (Gráfico 2), de um modo geral apresenta uma resistência estomática maior que Phthirusa micrantha, mas esta variação é relativamente pequena.

A observação da epidierme superior e inferior da Phthirusa rufa mostrou que, como Phthirusa micrantha (Braga, inédito), possui estômatos em ambas as faces.

\section{DISCUSSÃO}

Sabe-se que as plantas que crescem em pleno sol e solo arenoso, geralmente possuem mecanismo contra a perda de água; no entanto, para uma planta hemiparasita, quanto maior for a perda de agua, maior será o suprimento de água e nutrientes que chegarão até às folhas; portante, é de se esperar que a mesma não tenha mecanismos que controlem a perda d'água. A presença de estômatos tanto na epiderme superior como inferior reforça esta su- posição, por este motivo, podemos esperar que o hospedeiro em condições de alta insolação, venha a sofrer muito com a perda de água e possivelmente chegue a morrer.

Uma provável adaptação à condição de hospedeiro seria o fato destas plantas apresentarem uma resistência estomática maior que a hemiparasita nas horas de maior calor e intensidade luminosa.

No que se refere a ocorrênçia de Phthirusa micrantha e Phthirusa rufa não podemos afirmar quais os parâmetros que determinam a notada especificidade de germinação e crescimento sobre as espécies Hirtella racemosa e Ouratea spruceana.

Ein excursão à campina do Cacau-Pirêra (Estrada da Terra Preta) foi-nos possível verificar, rápidamente, uma grande ocorrência de Phthirusa micrantha sobre Glycoxylon inophyllum e Protium hetaphyllum. Foi feita uma observação de Phtrirusa micrantha e Phthirusa rufa sobre Couepia racemosa (Chrysobalanaceae) na referida campina.

A especificidade de Phthirusa micrantha e Phthirusa rufa na campina do $\mathrm{km} 62$ pode estar ligada a fatores como $\mathrm{pH}$ (dos hospedeiros). aspectos de dispersão das sementes, etc.

Uma comparação com a campina do CacauPirêra permite-nos dizer que esta especificida. de não é obrigatória, principalmente, em relação à Phthirusa rufa e Ouratea spruceana; mas em relação à Phthirusa micrantha chamou-nos atenção o fato de que na falta de Hirtella racemosa Lam. var. racemosa, esta planta teve o seu habitat em espécimes da mesma família (Chrysobalanaceae); podendo-se conjecturar o fato desta ocorrência estar correlacionada à visita de passáros que possuam preferência por frutos destas plantas.

\section{3 - OCORRENCIA DE ALGUMAS EPIFITAS NA CAMPINA E CAMPINARANA}

\section{INTRODUÇÃo}

Nota-se entrando na campina e campinarana que certas árvores suportam um grande número de epífitas, outras não. Interessou-nos relacionar o fato com algumas causas possiveis, como por exemplo o pH, disposição da planta epífita na árvore suporte, tipo de vege- 
tação (campina ou campinarana) e umidade relativa. Apenas estes aspectos foram considerados, mas, sabemos que muitos são os fatores que influenciam tal situação.

\section{MATERIAL E MÉTODO}

Foram escolhidas cinco espécies de árvores que tanto ocorrem na campina aberta e sombreada como na campinarana, que são:

- Leguminosae - Aldina heterophylla Spr. ex Benth.

- Leguminosae - Swartzia dolicopoda Cowan.

- Sapotaceae - Glycoxylon inophyllum (Mart. ex Miq.) Ducke.

- Ochnaceae - Ouratea spruceana Engl. - Rubiaceae --- Pagamea duckei Standl.

Tanto na campina como campinarana, foram anotadas as epifitas (com exceção de Orchidaceae, Bromeliaceae e Pteridophytae - assunto que será abordado em outras publicações desta série) que ocorriam em cinco indivíduos de cada espécie acima citada. De cada árvore foi feita uma raspagem do substrato para posterior medida de $\mathrm{pH}$. Foi também anotado a que altura da árvore ocorria a planta epífita, e se esta se encontrava nos galhos ou no tronco principal.

O aparelho utilizado para as medições de $\mathrm{pH}$ foi o mod. Prázisions $\mathrm{pH}$ meter, $\mathrm{pH} 391$ Wiss. Techn. Wërkstátten.

O material coletado foi triturado em liquidificador com $50 \mathrm{cc}$ de água destilada, filtrado e depois de 24 horas foram obtidas medições no potenciômetro.

Foi coletado material botânico e identificado por comparação com as plantas do Herbário do INPA. As amostras testemunhas são as mesmas citadas no trabalho de Anderson et alii, (1975), com algumas exceções, as quais indicamos na lista das espécies que ocorrem na campina e campinarana.

\section{Resultados}

As espécies epífitas que ocorrem na campina e campinarana são :

- Guttiferae - Ciusia cf. nemorosa G.
F. W. Meyer (pseudo-
epífita).

Estudos sobre a vegetação...
- Araceae - Anthurium gracile (Rud- ge) Engl. - B. de Albu- querque 1076 INPA, .... 48627.
Philodendron sp. - P.I.S. Braga 2923 et M.M.N. Braga, INPA, 50143.
- Gesneriaceae - Codonanthe sp.
Codonanthopsis aggrega- ta (Mart.) Hoehne.
Codonanthe sp. - P.I.S. Braga 2928 et M.M.N. Braga, INPA 49725.
- Ochnaceae - Ouratea spruceana Engl.
- Cactaceae - Epiphyllum phyllanthus (L.) Haw. - P.I.S. Bra- ga 2924 et M.M.N. Bra- ga, INPA 50144.

$\mathrm{Na}$ tabela 5 e 6 estão relacionadas estas espécies com a respectiva ocorrência nas árvores suportes, medidas de altura, $\mathrm{pH}$ e pcsição na árvore (galho ou tronco).

Anthurium gracile e Codonanthe sp. são as espécies encontradas em maior número (ver tabela 5 e 6).

Não existe uma relação entre as medidas de $\mathrm{pH}$ e número de indivíduos de cada árvore; apenas no macucu (Aldina heterophylla) observa-se um aumento no número de indivíduos com aumento concomitante de $\mathrm{pH}$ (ver gráfico 3 e 4).

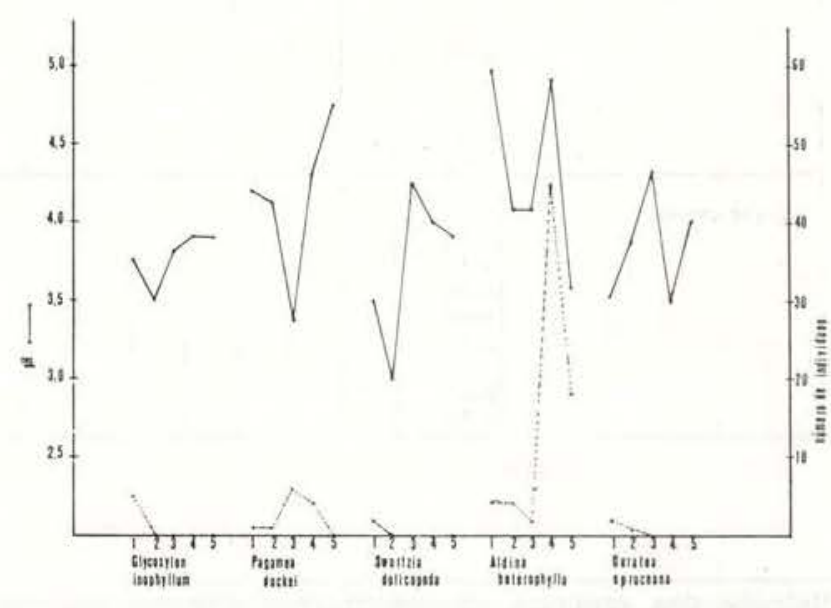

GRAFICO 3 - Relação entre a medida de pH e o número de indivíduos epífitas em cada árvore na campina sombreada. 
TABELA 5

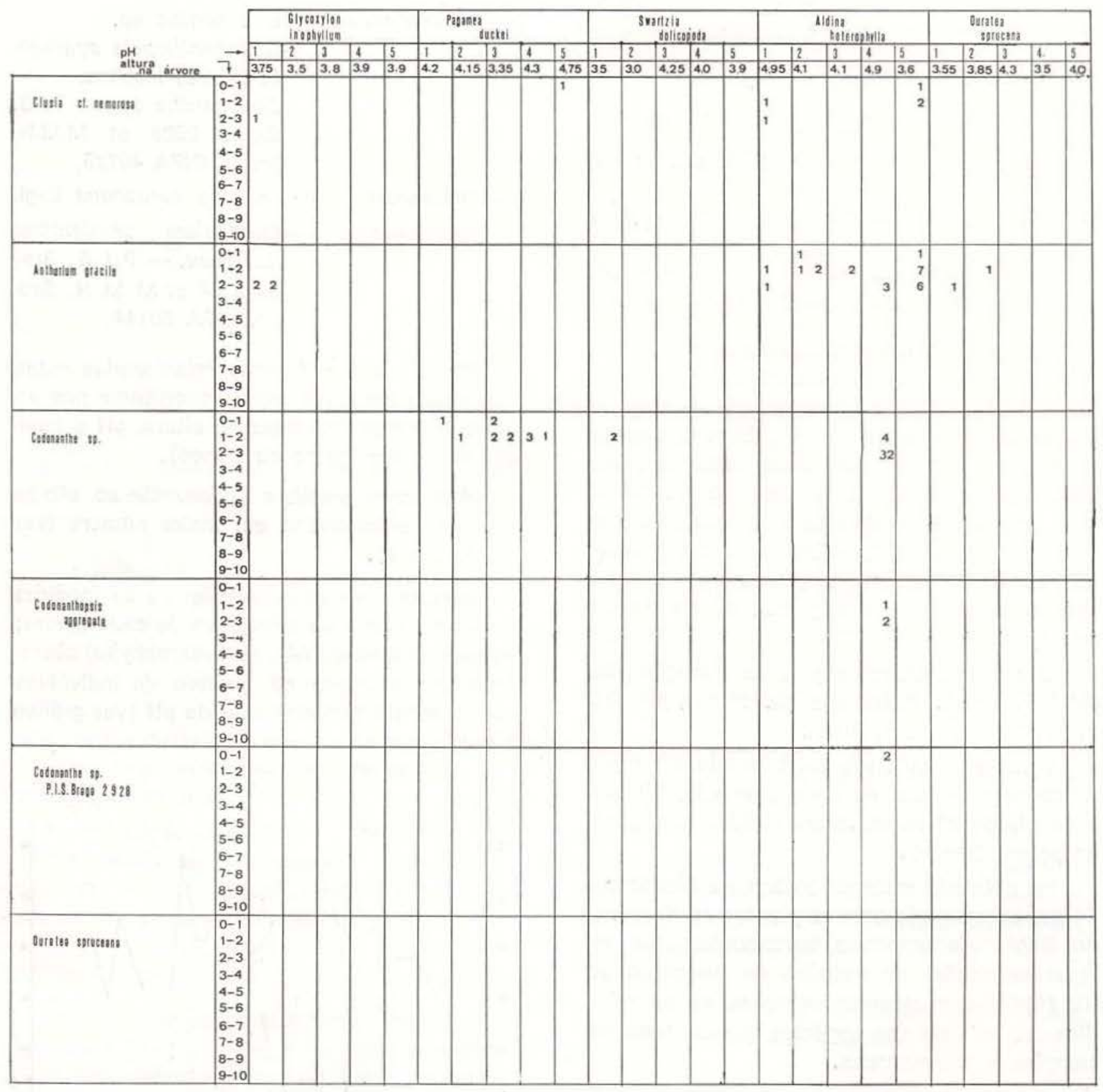

Relação das espécies, ocorrência nas árvores suportes, medidas de altura, pH e posição na árvore, de plantas da Campina sombreada. 
TABELA 6

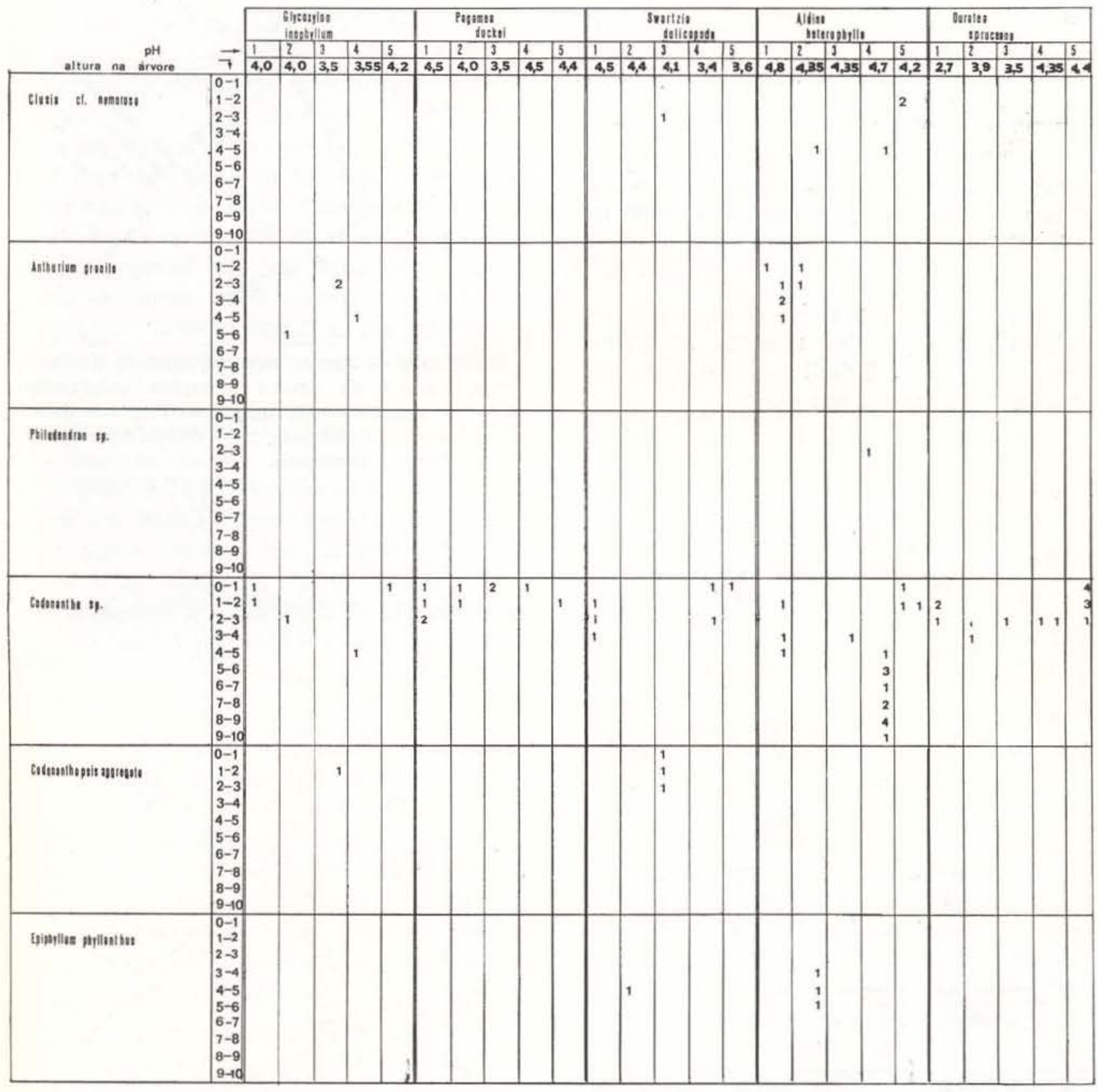

Relação das espécies, ocorrência nas árvores suportes medidas de altura, pH e posição na árvore, de plantas da Campinarana 


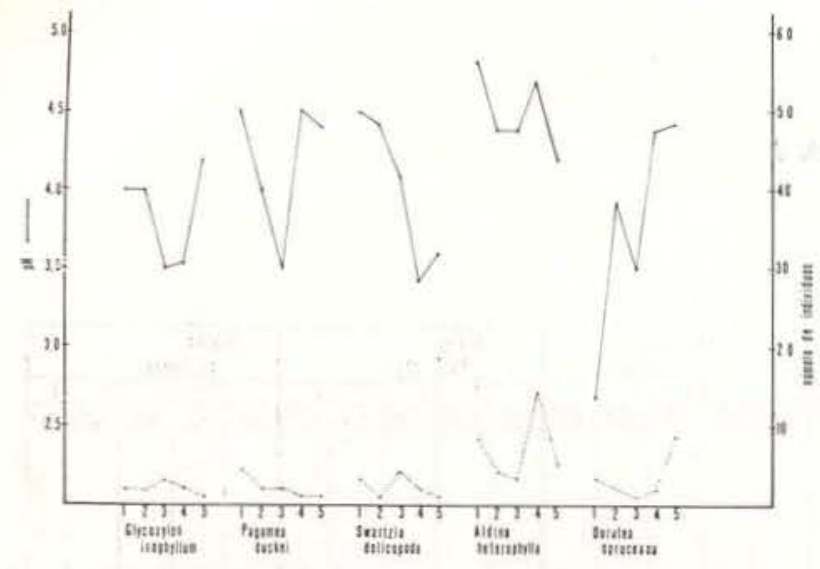

GRÁFICO 4 - Relação entre a medida de $\mathrm{pH}$ e o número de indivíduos epífitas em cada árvore na campinarana.

No gráfico 5 temos dados de número de indivíduos e posição dos mesmos na árvore (tronco ou galho). É facil verificar a grande ocorrência de epífitas nos galhos.

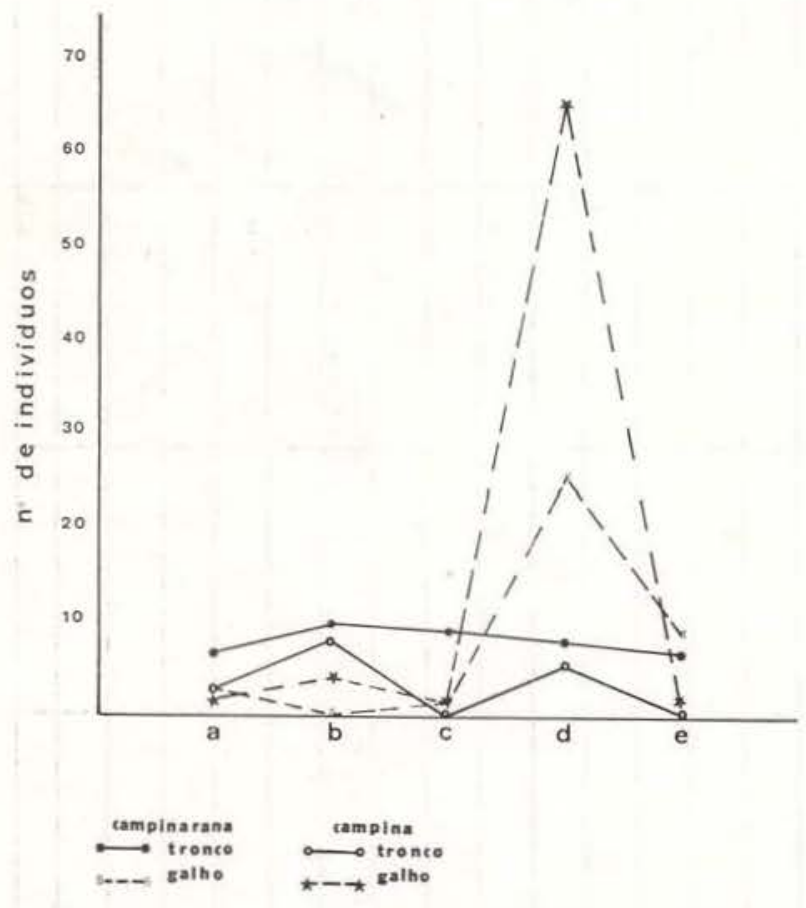

GRAFICO 5 - Número de indivíduos e posição dos mesmos nas árvores.

Nos gráficos 6 e 7 relacionamos: árvore suporte, número de indivíduos e altura na árvore. A maioria das epífitas ocorre até cerca de cinco metros de altura.

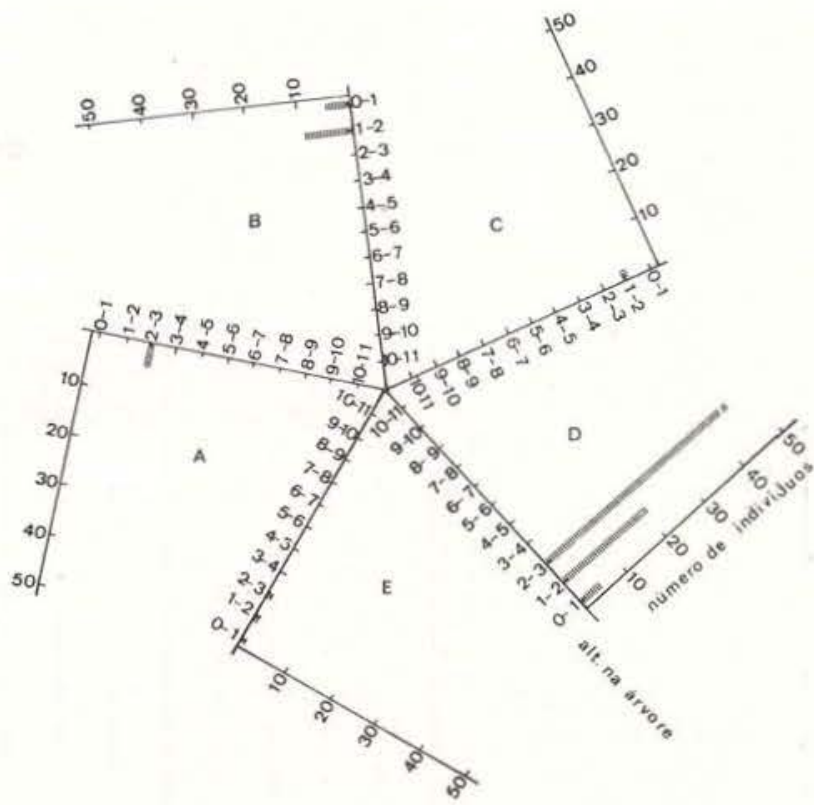

GRAFICO 6 - Árvore suporte, número de individuos e altura na árvore (campina sombreada). A - Glycoxylon inophyllum, B - Pagamea duckei, C - Swartzia dolicopoda, D - Aldina heterophylla, E - Ouratea spruceana.

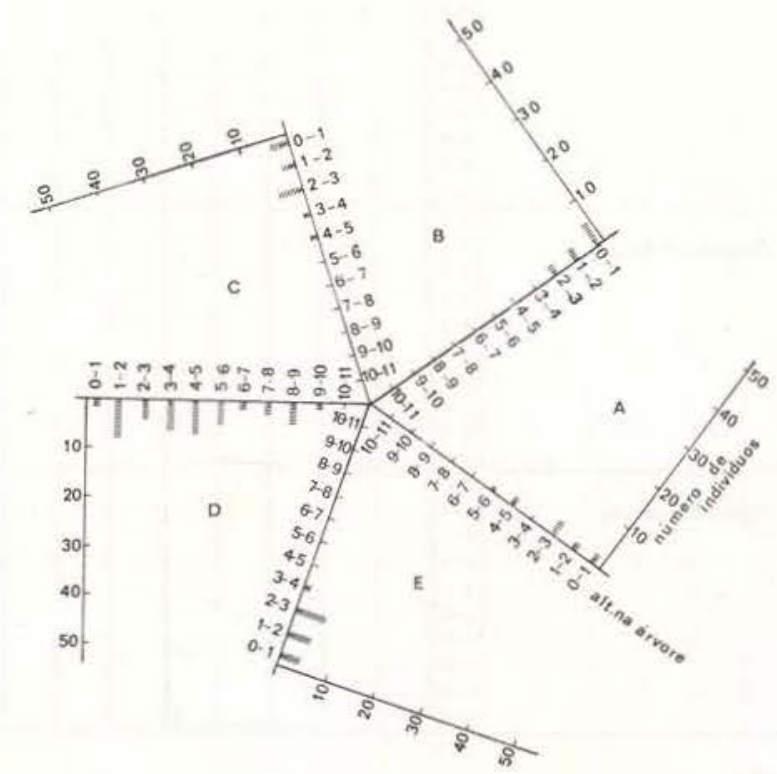

GRAFICO 7 - Árvore suporte, número de indivíduos e altura na árvore (campinarana). A Glycoxylon inophyllum, B - Pagamea duckei, C - Swartzia dolicopoda, D - Aldina heterophylla, E - Ouratea spruceana. 


\section{CONCL.USÕES}

A ocorrência de epifitas na campina e campinarana é muito representativo; no entanto, nem todas as árvores oferecem características físicas apropriadas para o desenvolvimento de epífitas.

De todas as árvores estudadas, a que nos forneceu grandes resultados numéricos e de diversidade de epífitas foi Aldina heterophylia (ver tabela 5 e 6), o que não surpreende aqueles que conhecem a campina e campinarana. Tal resultado pode muito bem ser entendido se visualizarmos Aldina heterophylla: uma árvore muito ramificada, cujos galhos são sem duvida alguma, uma boa plataforma de pouso para sementes. Naturaimente, outros fatores como por exemplo: tipo de casca, retenção de água e nutrientes disponiveis estão relacionados.

Os resultados das medidas de $\mathrm{pH}$ tiradas de todas as árvores não mostram ter relação (ver Gráfico 6 e 7) com o número de indivíduos; mas, em Aldina heterophylla podemos notar que existe um certo paralelismo entre $\mathrm{pH}$ e número de indivíduos. É óbvio, que, para realçar e explicar a importância do $\mathrm{pH}$ para o desenvolvimento das espécies epifitas ocorrentes, teriamos que fazer experiências neste sentido.

A segunda contribuinte como suporte para o desenvolvimento de epífitas que obtivemos foi Pagamea duckei. Naturalmente, não podemos comparar Pagamea duckei com Aldina heterophylla. É necessário considerarmos que Pagamea duckei é uma árvore relativamente pequena, com galhos finos, mas com uma casca cheia de reentrâncias que permite o desenvolvimento de sementes.

Sem dúvida, o taınanho da árvore, ramificação, etc., não só restringem o número de indivíduos como a diversidade de espécies. Assim, podemos observar que nas outras espécies de árvores diminui tanto o número de espécies quanto de indivíduos. Estas árvores, geralmente, têm casca lisa ou perdem-nas regularmente; isto faz com que os indivíduos epífitas que alí se desenvolvam tenham raízes que logo se enrolam no caule (da árvore suporte) ou tenham um hábito volúvel e logo se fixem.

A ocorrência das epífitas até mais ou menos cinco métros de altura poderia estar relacionada com o fator luz ou água. Walter (1971) acredita que em alguns casos o principal fator seja água. Apenas aquelas espécies que desenvolvem um parênquima aqüífero ou outros mecanismos para obtenção e armazenameto de água é que alcançam alturas maiores.

Outra comparação que poderíamos fazer é quanto ao número de espécies epífitas na campina sombreada e campinarana. Esta diferença não foi grande (ver tabela 5 e 6), pois a campina sombreada tem uma condição de umidade relativa similar à campinarana; entretanto, se observamos os dados de Ribeiro \& Santos (1975), poderemos notar uma diferença bem significativa de $8,5 \%$ entre campinarana e campina aberta.

Observando os dados de sucessão (Estudo $n .^{\circ} 1$ ), poderemos constatar que a diversidade de epífitas é muito pequena na campina aberta, o que nos permite correlacionar o fator umidade como um dos parâmetros que concorre para tal situação.

\section{Agradectmentos}

Agradecemos ao Dr. Ghillean T. Prance, pela orientação e confecção do sumário em inglês; ao Sr. Anthony Anderson que nos forneceu a idéia básica para realização do trabatho; ao Ms. Raimundo Barros, pesquisador da CEPLAC, pelo empréstimo do aparelho de medição de resistência estomática; ao colega $\mathrm{Pe}$ dro Nonato da Conceição, pela ajuda na preparação dos dados de resistência estomática; à coiega Raimunda Vilhena pelo empréstimo das lâminas contendo cortes histológicos de Phthirusa micrantha; à colega Izonete Araujo pelo auxílio na correção do Português; ao Sr. Basilio Pinto dos Reis que nos auxiliou na coleta de dados noturnos; ao Setor de Ciências do Ambiente, no nome dos Pesquisadores Umberto dos Santos e José Henrique Carrera: pela utilização do seu laboratório e finalmente à Sra. Osmarina Santos de Oliveira, a quem devemos a datilografia deste trabalho. 


\section{SUMMARY}

We investigated three ecological aspects of the vegetation of an Amazonian campina. The subjects studied were chosen to complement the study of Anderson et alii (1975) and the thesis studies of students of INPA.

The first part is an analysis of the small islands of vegetation which occur in the open campina. We found a total of 25 species of woody plants and we also studied some herbaceous species. Data is presented on the occurrence of species and the associations petween them and their correlation with island size.

The second part is a study of two species of Loranthaceae (Phthirusa rufa (Mart.) Eichl. and P. micrantha Eichl). These hemi-parasites occur in the open and shady areas of the campina and show a tendency to have specific hosts, especially Hirtella racemosa Lam. var racemosa (Chrysobalanaceae) in the case of P. micrantha, and Ouratea spruceana Engl. (Ochnaceae) in the case of $\mathbf{P}$. rufa. Some anatomical and ecophysiological aspects of this host-parasite relationship are also discussed.

The final part is an analysis of the occurrence of some selected species of epiphytes in five species of trees which are common in the campina. The study was made in both sun and shade campina, and also in campinarana.

\section{BIBLIOGRAFIA CITADA}

ANderson, A.B.; Prance, G.T. \&

ALBUQUERQUE, B.W.P. DE

1975 - A vegetação lenhosa da Campina da Reserva Biológica INPA-SUFRAMA (Manaus-Caracarai, $\mathrm{km} \mathrm{62)}$. Acta Amazonica, Manaus, 5(3): 225-246.

LISBôA, P.L.

1975 - Observações gerais e revisão bibliográfica sobre as Campinas Amazônicas de Areia Branca. Acta Amazonica, Manaus, 5(3): $211-223$.

ODUM, EUGENE P.

1969 - Ecologia, Bib. Pion. Biol. Mod., Trad Kurt G. Hell, Ed. Univ, S.P. 201 p.

Pibeiro, M. de N.G. \& Santos, A. dos

1975 - Observações microclimatológicas no ecossistema Campina Amazônica. Acta Amazonica, Manaus, 5(2):

TURner, N.C. \& Parlange, J.Y.

1970 - Analysis of Operation and Calibration of a ventilated Diffusion Parameter Plant Physiology, 46: 175-177.

Walter, Heinrich

1971 - Ecology of Tropical and Subtropical Vegetation. English Translation. Oliver \& Boyd. Ed. J. H. Burnett. Britain. $539 \mathrm{p}$. 